\title{
School Leaders' Experiences of Implementing Education for Sustainable Development-Anchoring the Transformative Perspective
}

\author{
Anna Mogren * and Niklas Gericke \\ Department of Environmental and Life Sciences, Karlstad University, Universitetsgatan 2, 65188 Karlstad, \\ Sweden; niklas.gericke@kau.se \\ * Correspondence: anna.mogren@kau.se
}

Received: 8 May 2019; Accepted: 12 June 2019; Published: 17 June 2019

\begin{abstract}
In this article, we consider the problem of ensuring that Education for Sustainable Development (ESD) is firmly embedded in a school through appropriate management and planning of the school's activities (or characteristics of the school organization). To this end, we identify the domains of school organization that would benefit from particular structures and routines in order to embed ESD. We identify these domains by thematically analyzing responses of interviewed leaders of schools employing a transformative approach to ESD. We divided the leaders into two groups, based on the extent to which their respective schools employed a transformative approach to ESD. We analyzed the differences in responses of the two groups, enabling us to identify and compare the structures that school leaders in the respective groups believe to be important. In addition to reporting the results, we discuss their implications. We focus particularly on how structures identified by leaders of highly transformative schools could contribute to long-lasting transformative implementation of ESD, and how structures identified by leaders of the other group could be used to circumvent barriers to such implementation.
\end{abstract}

Keywords: education for sustainable development (ESD); ESD implementation; transformative schools; school leaders; school organization; upper secondary schools

\section{Introduction}

National evaluations as well as developments in society suggest the effects of Education for Sustainable Development (ESD) initiatives to secure a sustainable future by educational means have been disappointing [1]. Large scale programs on ESD have been launched [2-4]. Studies have shown that effects of these implementations are not long-term [5]. Hence, the difficulties of implementing ESD in schools raises the question of how school leaders in ESD-active schools could use the organizational level to anchor and secure ESD over time in education.

Lotz-Sisitka et al. [6] has suggested that the shortage of transformative initiatives in education is to blame for the lack of widespread awareness of sustainable development. Arguments for a transformative based education builds on the aim of developing behaviors, attitudes and actions in line with ESD within educational settings [6,7]. Policy documents linked to research and politics such as the UN Agenda 2030 [8] describes the educational sector as important for moving away from unsustainable development. The key factor is to involve young individuals during their schooling and in that way make them engaged, informed and committed to work for a sustainable future.

The study described in this paper was based on prior research on the relationship between ESD-active school organizations and transformative education [9-11]. A school's 'organization' refers here to the day-to-day administration, staff development, routines, processes, networking 
and management of a school [7]. Recent studies have found that school organizations exhibiting transformative qualities-such as professional networks, school collaboration with society and student-centrered approaches - have also emphasized the importance of qualities related to structural anchors, such as permanent and stable settings in education like the schedule, locations and teachers' working units $[9,10]$. Together the two qualities make up the prerequisites for a practical application of ESD [10]. However, earlier ESD research indicated that dominant structures and routines hinder the establishment of a transformational school organization [6]. Other studies on ESD and policy advocate inclusion of both transformative changes and anchoring features in the school organization to establish and maintain high quality in education $[5,12,13]$. A complication is that earlier studies frequently refer to anchors in school organization rather vaguely, without providing empirical examples. Accordingly, our in-depth study was designed to identify the anchoring structures and routines that school leaders in ESD-active schools have suggested are important, and to understand implications of those anchors for transformative ESD implementation strategies. We also consider school organizations with less focus on implementing transformative ESD to identify barriers that might prevent successful ESD implementation at an organizational level.

\section{Background}

\subsection{ESD Implementation through Structures}

The investigation on transmissive emphasized qualities at school organizations in this study is made to outline their role in scaling up more transformative oriented ESD implementation, which is argued as important in ESD implementation research [6,7]. School organizations have been criticized for being too rigid and prescriptive to implement process-oriented transformative ESD approaches in established school contexts [14]. In this section, the critique of structural, transmissive ESD implementation programs and associated problems are summarized. However, we also present opposing arguments, recognizing the need for schools to use such structural programs as transmissive anchors in ESD implementation, despite their shortcomings.

Structural implementation programs are often used in efforts to scale up the impact of ESD initiatives, as illustrated by the following examples. The Eco school program involves 52 countries and 11 million students [15]. National and regional initiatives have been launched in numerous educational settings around the world, such as the Green School Alliance [16] in the USA, the Australian Sustainable School Initiative [17], Sustainable Schools in the UK [18] and the Award for Sustainable School Development in Sweden [19]. During the UN Decade of ESD (2005-2014) [20], national structural programs of ESD implementation were formulated in many countries [2,12]. However, implementation programs have been frequently criticized for specifying standards and goals in advance, thus hampering the ability to adapt to learning contexts in particular schools or regions [21]. Structural ESD implementation programs have also been criticized by some authors for having a rigid structure and being ineffective, or sometimes even detrimental, to sustainable development $[6,22]$. For example, themes of ESD structural implementation programs that have been prioritized due to predefined suggestions include waste separation and recycling, while ways to decrease amounts of waste generated and better solutions for disposing of waste have received much less attention. Another example of structural ESD implementation concerns the vegetarian lifestyle, which may generally boost sustainability by reducing 'greenhouse gas' emissions associated with meat production, but not necessarily in regions where vegetable energy sources cannot be produced year-round. Importing vegetables by air, sea or land is not always a sustainable alternative. A risk associated with embedding predetermined suggestions in implementation programs is that they may perceived as universal truths from the perspective of the program's designers, but may not be regarded in the same way, and thus may be counterproductive, in a particular context. 
Another risk of schools interpreting tools provided for ESD implementation as structural schemes for schools, and thereby failing to consider local school-level contexts, has also been recognized [23]. Descriptions of structural programs presented to schools may be uncritically accepted as lists of things that must be done, rather than applied in a transformative way to assist schools to realize and implement ESD within their organizations. Thus, a need for greater curiosity about factors that enhance implementation programs' long-term efficacy, beyond their mere presence in educational settings, has been noted (ibid.).

A problem is that structural implementation programs for ESD are frequently responses to political decisions that result in pressure on schools to transform education and become catalysts in the building of a sustainable society [24], but schools are always guided by a curriculum with predefined goals. Hence, school education is to some degree normative by definition. In this context, the available programs can be seen as easily accessible tools that enable educational systems to manage and understand the complex concept of ESD [25]. Another argument for use of ESD programs is that they have positive results, according to qualitative meta-studies. For example, they can reportedly contribute to general quality in education, increase schools' cooperation with local society, raise ESD's visibility in curricula and enhance students' abilities through various pedagogical methods (i.e., empower young individuals), which is regarded as a highly desirable element of ESD [26].

However, there is limited generalizable evidence that structured ESD implementation programs have positive educational effects [26-28]. Indeed, the few large-scale evaluations of ESD implementation efforts published to date indicate that they have little or no effect on students in terms of raised awareness, and behaviors or attitudes towards sustainable development [4,29-31]. Another problem regarding previous assessments of ESD programs' contributions to quality in education is that they have generally focused on how they may raise educational quality, rather than if they really do transform schools over time [23]. It is reportedly difficult to find studies of successful transformative approaches of ESD implementation [32]. Instead, role model schools are used in the short term as examples for schools wishing to learn about the power of transformative ESD implementation to address local and global sustainability problems $[26,31,33]$.

If schools continue to use structural implementation programs, it is essential to identify which anchoring structures allow and foster (or hinder) desirable transformation in education. Thus, here we explore relevant transmissive, structural and routine qualities at school organization level, which have previously received too little attention.

\subsection{School Organization Quality}

We now explain why quality is used as a generic concept in this study to understand how school leaders lead and shape their school organization.

School leaders' emphasis on transmissive qualities (anchors of structures and routines) or transformative qualities (changes and processes) generally indicates the educational perspectives that have shaped a school's organization [10]. Conversely, the educational perspectives underlying a school's organization are indicative of generic qualities that are associated with the school, and thus are supported and used by the school leader to organize the school. It has been claimed that efforts to implement ESD in a school must be aligned with the prevailing qualities of the school [34], i.e., identifying prevailing quality assumptions and linking them to ESD implementation programs is a more effective way of implementing ESD than viewing ESD as an 'add-on' to existing educational perspectives. Thus, knowledge of prevailing quality assumptions, which allows transformation in the school organization, has been regarded as 'firm ground' that is crucial for successful ESD implementation [33].

As detailed later, the empirical material analyzed and discussed in this paper was drawn from interviews with leaders of some of the most ESD-active schools in Sweden. Thus, a fundamental assumption is that some of the generic qualities identified in these schools can be regarded as part of the 'firm ground' of ESD implementation. The selection of schools was done to ensure that the 
qualities identified as important on the basis of the school leader' responses are indeed relevant to an ESD implementation. In the following paragraph, two educational perspectives expressed by the interviewed school leaders are outlined. In practice, a school organization must embrace both of these ideals, but there will inevitably be some variation in the emphasis placed on each of them by a particular school organization $[10,12]$.

\subsection{Educational Perspectives of ESD in Schools' Organizations}

As already mentioned, transmissive approaches focus on increasing schools' ability to implement ESD within existing school structures by defining and establishing routines and structures that control compliance with its tenets. In contrast, transformative approaches emphasize the need to develop schools by concentrating on educational processes rather than direct results in terms of predefined outcomes $[32,35]$. Study of these educational perspectives and their underlying values is believed to be important for enhancing the likelihood of success of ESD implementation programs offered to school organizations and school leaders (in terms of awards and standards) [36-38].

\subsubsection{Transmissive Anchors in the School Organization}

The term 'anchor' refers here (in the verb form) to the practical use of transmissive expressions (pedagogies, forms of learning and praxis [6]) in education, and more specifically the establishment and long-term realization of ESD within a school's organization. An anchor provides maintenance and stability, and gives both teachers and students security in the knowledge of what needs to be done and when it needs to be done (since ESD includes a strong educational ideal of process and change) $[9,10,13,39]$. Two main purposes of anchors in ESD have been highlighted from a German perspective [40]. One is clarification of the ESD perspective to raise support for ESD among decision-makers, politicians and the general public. The other is to embed the perspective in all sorts of educational activities and interactions, both within schools and with external stakeholders. Similarly, ESD anchoring has been defined as clarifying the purpose of ESD for colleagues, leaders and parents in such a way that ESD becomes accepted as part of education and non-negotiable [41]. Examples of transmissive anchors in a school's organization include:

a. Students work towards educational goals that ensure attainment of at least a minimum standard of relevant knowledge.

b. Organization of education based on the teacher's knowledge of curricular content.

c. Development of routines that ease short-term time burdens for pedagogical staff and protect them from adjustments prompted by changes and trends in society.

d. Routines that save time for the pedagogical staff, thus allowing them to spend more time with students.

It has been argued that transmissive elements can provide the stability and anchorage in education required for long-term realization of ESD [12]. On the other hand, as societal demands rapidly change, there are risks of anchors (structures and routines) being cemented in schools' organizations, and thus inhibiting the educational change and renewal necessitated by socio-economic and/or cultural developments [42]. Accordingly, an evaluation of ESD implementation in Australian schools concluded that current ESD program standards may specify transmissive anchors that are already outdated and of low relevance to a sustainable society [23]. However, here we argue that anchors related to highly transformative school organizations may differ from anchors initially established to enable ESD implementation.

\subsubsection{Transformative Expressions in the School Organization}

Schools that are actively implementing ESD are encouraged by scholars to increase transformative expressions in education [6,43]. New societal problems that cannot be addressed by existing solutions require new solutions, and education is a key contributor to identifying such solutions [23]. 
Transformative education aims to modify beliefs and assumptions, enabling decision-making that fosters creation and maintenance of a sustainable society built on a broad understanding of various values and interpretations of the world and how others are affected by decisions we make [44]. Transformative education is visible when the learner can use and judge knowledge to identify alternative solutions in relation to the local and global surroundings. With such understanding, learners can take informed, sustainable decisions and be aware of the decisions' consequences for themselves and others. Thus, young individuals can become actors in society who help to create a sustainable future during their education. Transformative processes and changes that enable these learning conditions for students are regarded as being highly important in research related to ESD e.g., $[6,12,32,38]$.

A transformative school will have leaders that emphasize certain features of their organization. Earlier research shows that a proactive leadership approach and links with the surrounding society are examples of such features [9]. Another key feature of transformative organizations that are actively implementing ESD is a student-centered organization [10]. It has also been suggested that an important feature required to transform the learners is a leadership mindset, for activities ranging from setting and maintaining moral purposes and key elements of transformative expressions in the school organization, such as [45]:

- focusing on students' learning processes, rather than the central content of a specific subject;

- building on the learners' interest and experience of what is important and needs to be learnt in relation to a societal problem or challenge;

- engaging students in interdisciplinary work, involving various subjects and thematic work to improve students' knowledge and meaning-making; and

- implementing processes that are intended to change present settings, anchors and routines of education and to introduce new knowledge and learning.

There is a risk that schools adopting a transformative mode of organizing education may not realize their ESD-related intentions, or only achieve short-lived changes rather than their higher ambitions. Often these schools are dependent on single individuals for their commitment to ESD, so-called 'driving souls' [46,47]. ESD is not then anchored within the routines and structures of the school organization, so its implementation is vulnerable if those 'driving souls' leave the organization. A lack of political and mandatory support, as well as networks of like-minded people, have been highlighted as possible reasons for failure to realize long-term intentions, such as prolonged commitment to ESD and preparation of future citizens for sustainability [48].

\subsection{A Mix of Transmissive Anchors and Transformative Expressions at School Organization Level}

The cited studies show that there is a thin line between a school organization that is excessively guided by transmissive qualities (with a risk of continuation of educational goals that are outdated and potentially incompatible with a sustainable society) and one that also recognizes the importance of transformative qualities. This study seeks to identify the virtues of established transmissive anchors in ESD-active schools and their role in ensuring the longevity of ESD implementation from a transformative perspective.

In the study we use quality criteria $(\mathrm{QC})$ as the unit of analysis to investigate the implementation of anchoring qualities that support ESD. On average, school leaders interviewed in previous investigations of ESD-active Swedish upper secondary schools regarded transformative qualities as being only slightly more important than transmissive qualities [10]. This finding conflicted with suggestions in the ESD literature, that a strong emphasis on transformative qualities is a clear sign of active and effective ESD implementation [43]. As already noted, transformation is seen as a way to help educational systems adjust to changes in society and impart the knowledge needed as a result of such changes, and young individuals' participation is crucial for transforming society [33,34]. One could therefore expect a higher degree of transformative expression within ESD-active schools than in schools generally. 
However, the conventional way of managing and directing a school organization, including ESD schools, is characterized by transmissive qualities, with an emphasis on individual evaluations and judgements of student accountability, which is a long-lasting goal of Swedish education and civil servants. There is some similarity between Max Weber's ideas of rational organizations [49] and school organizations that emphasize transmissive qualities, since they both focus on learners as objective stances in set school structures. Transformative qualities, in contrast, embrace subjective views of learners in seeking solutions that could also change the structures of a school's organization. It has been suggested that the transmissive qualities are such important inherent elements of the rational school organization that it would be difficult for schools to challenge them or embrace a higher degree of transformative qualities [28]. Hence, it is of interest to study the transmissive qualities in ESD schools to identify those that could potentially anchor (or hinder establishment of) a transformative perspective within these schools.

\subsection{ESD Quality Measures}

The schools led by the respondents in this study were investigated in earlier studies in terms of their focus on quality, particularly two quality parameters at both school leader level [10] and teacher level [11]. In the analysis presented here we used the quantitative results obtained as proxies for transformative quality measures at the school level, enabling separation of school organizations in accordance with their level of focus on transformative quality.

The first parameter used to judge quality is the transformative quality index (TQ index: 0 to 1 ), derived by assessing the weighting of transformative qualities expressed by school leaders when asked to share their views on high quality in their school's organization [10]. It is based on qualities of a hypothetical 'transformative role model school' that incorporates all of the transformative qualities identified in an earlier study with the same set of ESD-active schools as in this study. The TQ index takes into account the actual number of transformative qualities implemented in a school's organization, as well as the emphasis placed on each of them by the school leaders. The judgement of expressed qualities is described in detail in a previous article [10].

The other quality parameter is an operationalization of a theoretical model, called the Scherp model, developed in school improvement research, which outlines the dimensions of a school's organization and their coherence (which is regarded as facilitating high quality in teaching and learning). The model includes four dimensions, three of which are: the vision of a school, structures and routines in the school's organization and professional knowledge creation (a process-orientation dimension). Productive interaction in these three dimensions supports the fourth dimension: the pedagogical practice. The parameter used to gauge the interaction between all the school dimensions is called school organization coherence $[11,50]$. This parameter of the Scherp model can be used to measure the emphasis on transformative process and change in a school's organization, which can be used to evaluate the kind of ESD implementation taking place. The model was operationalized in the form of a teacher survey and distributed in an earlier study [11], results of which are used here.

Together the two parameters provide a way to measure transformative quality at the schools in the study. Moreover, the two previous studies obtained coherent results from both school leaders and teachers, indicating their validity. Therefore, we used these measurements to identify and select schools working from two distinct educational perspectives: a predominantly transformative perspective and a predominantly transmissive perspective. Then, we compare how school leaders in these two groups of schools use anchoring structures to make these educational changes (the transformation perspective) permanent in their respective organizations.

\section{Aim and Research Questions}

The aim of this study is to investigate where school leaders of ESD-active schools believe it is important to anchor the transformative perspective of education. We investigate the transmissive expressions as anchoring qualities within the school organization and whether they facilitate or 
create barriers to a successful transformative ESD implementation. Two selected groups of schools with differing focus towards transformation in their school organizations are compared in order to identify any differences in how school leaders express and prioritize anchors in ESD implementation. Knowledge of which anchors result in a long lasting transformative ESD implementation can lead to recommendations that effect a transformative focused ESD implementation. In contrast, highlighted anchors by school leaders with less focus on transformative quality in ESD implementation are discussed as possible barriers to ESD implementation. In summary, this study seeks to address the following question:

Which domains of the school organization do school leaders find important in anchoring ESD to make it permanent and long lasting?

\section{Method}

\section{Research Design}

The empirical analysis was based on data obtained in interviews with 14 leaders at 10 upper secondary schools in Sweden, which were known to be actively implementing ESD at the time of data collection [9,10], due to both the selection method used and confirmation by the schools themselves. Thus, they provided suitable environments for learning about school organizational-level aspects of ESD implementation.

The analysis drew on previous studies on views of school leaders and teachers regarding transformative education and related issues to identify domains of school organization within which a transformative perspective must be anchored to achieve long-lasting ESD implementation [11]. The prior studies had addressed school leaders' views on quality and emphasis on transformation in education $[9,10]$ and teachers' perceptions of transformative qualities of the organization in the same schools [11]. Results of these studies were used to categorize the schools in this study, based on the degree of transformation detected in their organizations [9-11]. The focus here is on the domains that school leaders viewed as important to anchor ESD in the schools, as revealed by their responses in interviews. Some of the methodological steps involved are described in detail in previous papers [9-11] and are summarized below.

Domains identified as anchors in the schools with relatively strong and weak transformative orientation are later discussed as potential facilitators and hindrances of successful ESD implementation, respectively. Qualitative interpretation of responses in the interviews enables us to identify the school leaders' reasons for specifying specific domains as anchors for ESD in their school's organization.

Step 1-Selection of school leader informants.

The schools included in this study were selected to be representative of the Swedish schools that were most actively implementing ESD at upper secondary level at the time of data collection. The selection of schools was guided by a theoretical eclectic approach [9], based on two sets of QC (related to content and learning processes) for identifying ESD-active schools. Using these criteria, two groups of Swedish upper secondary schools were selected, as described in more detail below, and a final group of 10 schools participated.

Candidate schools for the first group were extracted from three national data registers-lists of schools given awards under the Award for Sustainable Development program [18], the Green Flag schools program [51] and The Global School program [52]. Those national registers are the most comprehensive available sources of data on schools involved in ESD activities across Sweden $[9,10]$. Criteria based on the degree of participation in those ESD programs were used to rank schools, then external stakeholders validated candidate schools' activity in the programs before a final set (of seven) schools was selected [9].

A second group of three schools was selected based on their engagement in a network implementing ESD through interdisciplinary studies without any official certification. These schools were selected to ensure the inclusion of schools where ESD is implemented through an interdisciplinary approach, 
which is characteristic of transformative ESD implementation [37]. The second group of schools were validated in the same manner as the first group [9].

Step 2-Data collection.

Semi-structured interviews were conducted with school leaders at the ESD-active schools to identify qualities they believed to be highly important. They were inductively asked to express how their school organization maintained and developed high quality education. As qualities were expressed by school leaders, complementary questions were asked to obtain information on the respondents' personal opinions about meaningful aspects of the qualities. The interviews were audio-recorded and concept maps portraying the school leaders' understanding of high quality in their school organization were constructed while the interviews were in progress using a method developed by Scherp and Scherp [50]. These maps, together with transcripts of the interviews, provided the empirical foundations for the subsequent analyses-to identify generic QC that sets of the school leaders believed to be important $[9,10]$.

Step 3-Separating schools based on their focus on transformative quality.

This methodological step was used to determine whether a participating school exhibited a high or a low degree of transformative quality in ESD implementation. We constructed a continuum of schools based on two parameters that measure transformative quality in the participating schools, as described in the background section. The first was used to measure the transformative quality of the schools' organization, based on responses of 14 school leaders in interviews [9]. The second was based on the responses of 53 teachers to a questionnaire [11] concerning the transformative quality of their respective schools' organization. Together, these two parameters were used to cluster the schools into three groups with differing quality of transformative ESD implementation, as shown in the matrix in Table 1. The horizontal axis of the matrix shows the TQ index, based on data obtained from school leaders' responses in percentages, which are positively related to the leaders' perceived transformative degree of their schools [10]. The vertical axis shows the coherence of the schools' organizational dimensions, according to the Scherp model, on a Likert scale from zero to four, where four is the highest coherence, used here as a proxy indicator of a school organization with very high transformative quality [11].

Three groups of schools were identified, based on agreement between the values of the two parameters, as shown in Figure 1. Of these three groups, the two at the ends of the continuum (Figure 1) were selected for further analysis. These two groups each include three schools: one representative of schools with a strong focus on transformative education (group 3), and the other representative of schools with a relatively weak focus (group 1).

Table 1. Measures of the two parameters on transformative ESD quality. The vertical axis shows school organization coherence $0-4$ [11]; the horizontal axis shows the transformative quality (TQ) index $0-1[10]$.

\begin{tabular}{ccc}
\hline \hline TQ Index Based on School Leaders' Responses & $\begin{array}{c}\text { Under 0.5 } \\
\text { Coherence of School Organization Based on Teachers' Responses }\end{array}$ & $\begin{array}{c}\text { Average Higher } \\
0.6\end{array}$ \\
\hline $\begin{array}{c}\text { Less than } 2.5 \text { (average 2.44) } \\
\text { than } 0.7\end{array}$ & 3 schools \\
Higher than 2.5 (average 2.63) & 2 schools \\
& 3 schools \\
\hline
\end{tabular}

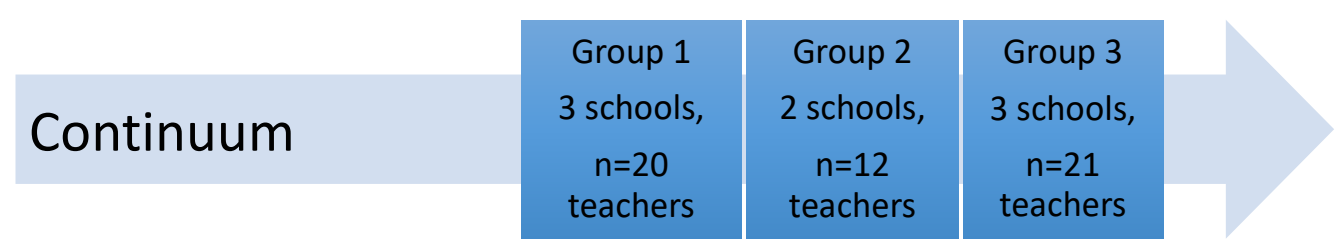

Figure 1. Groups of schools along a continuum based on the two measures of transformative quality in Education for Sustainable Development (ESD) implementation as presented in Table 1. Schools in groups 1 and 3 are regarded as having relatively low and high levels of transformative quality, respectively. 
Step 4-Identification of transmissive qualities.

In a previous study [9], 26 QC were identified from the interviews with school leaders, based on the concept maps and transcripts of the interviews [9]. The underlying objectives related to each quality criterion were analyzed to separate transformative expressions related to them from the transmissive expressions. Each QC was then weighted as being mainly transformative or transmissive, based on the expressed views of school leaders, according to numbers of transmissive and transformative reasons given by the school leaders for it. The calculations and a more detailed description of the weighting process are outlined in one of the previous studies [10] (pp. 1002-1003), in which we also analyzed the transformative weighted QC [10]. In the analysis reported here, we evaluated ways in which school leaders use transmissive qualities to anchor ESD in their respective schools' organization in efforts to embed it permanently.

Step 5-Identification of transmissive weighted QC of high importance in group 1 and 3 schools.

We are interested in the QC that were highlighted by school leaders as being especially important for anchoring quality in group 1 and 3 schools. We produced three rankings: the first ranks each QC (from 1 to 26) based on overall views of the school leaders. The second and third rank them in terms of importance from a transmissive anchoring perspective, based on responses of leaders of group 1 and group 3 schools (as defined in step 3), respectively. The most important anchors were identified by comparing differences between overall rankings of the $\mathrm{QC}$ and their rankings by leaders of the two groups of schools. This procedure (applied separately to data for both groups of schools) enables identification of QCs associated with transmissive or transformative orientation. The rankings for each QC are displayed in brackets in Table 2, which facilitates identification of QC that are significant from a transmissive perspective. A higher ranking in the second column (group 3 schools) than in the first, for example, indicates that a QC is important for school leaders at schools with a transformative perspective.

Table 2. Quality criteria (QC) and their summed quality importance scores with rankings. Column A shows the overall QC scores without weighting. Colum B and C show the transmissive weighted QC for group 1 (C) and group 3 (B) schools.

\begin{tabular}{cccc}
\hline & A & B & C \\
\cline { 2 - 4 } Quality Criteria, QC & All Schools & Group 3 Schools & Group 1 Schools \\
\cline { 2 - 4 } & & (Transformative Schools) & (Transmissive Schools) \\
\cline { 2 - 4 } & $\mathbf{n}=\mathbf{1 0}$ Schools & $\mathbf{n}=\mathbf{3}$ Schools & $\mathbf{n}$ = 3 Schools \\
\cline { 2 - 4 } & $\mathbf{( R a n k )}$ & $\mathbf{( R a n k )}$ & (Rank) \\
\hline Creation of holistic idea & $38(1)$ & $18(11)$ & $32(6)$ \\
Target for planning school organization & $36(2)$ & $25(9)$ & $44(2)$ \\
Team structure at school & $32(3)$ & $40(3)$ & $55(1)$ \\
Leadership focus & $32(4)$ & $52(2)$ & $37(5)$ \\
Implementation of holistic idea & $31(5)$ & $27(7)$ & $38(4)$ \\
Understanding of the holistic idea & $31(6)$ & $12(15)$ & $10(15)$ \\
Proactive leadership & $28(7)$ & $35(4)$ & $40(3)$ \\
School climate & $28(8)$ & $32(5)$ & $15(12)$ \\
School identity in society & $27(9)$ & $28(6)$ & $8(17)$ \\
External expectations & $25(10)$ & $18(11)$ & $26(7)$ \\
Professional networks & $22(11)$ & $12(15)$ & $26(7)$ \\
School governance & $21(12)$ & $8(18)$ & $24(9)$ \\
Long term plans & $20(13)$ & $2(24)$ & $24(9)$ \\
School collaboration with society & $19(14)$ & $9(17)$ & $8(17)$ \\
Role model leadership & $18(15)$ & $16(13)$ & $18(10)$ \\
ESD as a point of departure for & $17(16)$ & $55(1)$ & $0(23)$ \\
organizing the school & $16(17)$ & $6(23)$ & $14(13)$ \\
Evaluation purpose & $15(18)$ & $24(10)$ & $2(21)$ \\
Inner conviction, vision, philosophy & & &
\end{tabular}


Table 2. Cont.

\begin{tabular}{cccc}
\hline & A & B & C \\
\cline { 2 - 4 } Quality Criteria, QC & All Schools & Group 3 Schools & Group 1 Schools \\
\cline { 2 - 4 } & & (Transformative Schools) & (Transmissive Schools) \\
\cline { 2 - 4 } & $\mathbf{n = 1 0 ~ S c h o o l s ~}$ & $\mathbf{n}=\mathbf{3}$ Schools & $\mathbf{n}=\mathbf{3}$ Schools \\
\cline { 2 - 4 } & (Rank) & (Rank) & $5(20)$ \\
Trans-disciplinary scheduling & $14(19)$ & $8(18)$ & $16(11)$ \\
Partial ESD implementation in school & $13(20)$ & $8(18)$ & $13(14)$ \\
School leader teamwork & $11(21)$ & $26(8)$ & $1(22)$ \\
Schternational outlook & $10(22)$ & $15(14)$ & $0(23)$ \\
ESD quality measurement & $10(23)$ & $2(24)$ & $6(19)$ \\
Resistance of ESD implementation & $7(24)$ & $8(18)$ & $10(15)$ \\
ESD purpose & $4(26)$ & $1(26)$ & $0(23)$ \\
\hline
\end{tabular}

Step 6-Identification of anchors for ESD in a school's organization.

Step 5 identified QC with apparent importance for transmissive qualities. However, the QC do not, by themselves, indicate structures and routines that are important anchors because they refer to transformative as well as transmissive qualities. Therefore, we conducted a thematic content analysis [53-55] using all transcripts relating to all QC that were positively ranked from the transmissive perspective. The material from the transcripts was coded, by group, into themes related to 'anchoring'; i.e., important domains in a school's organization where structures and routines could be established to implement ESD effectively and permanently. Excerpts from the transcripts are used in the results section to justify and explain the reasons for particular categorizations.

\section{Results}

First, we present the QC rankings to provide transparency about the QC used in the thematic analysis. The results show differences in beliefs of the leaders of the two groups of schools about the relative importance of each QC for anchoring ESD implementation in school organizations. The quality importance scores obtained for all QC are shown in Table 2. Scores in the first column of the table indicate their importance based on the school leaders' responses, with no weighting (i.e., regardless of the school leaders' intention to use the $\mathrm{QC}$ as an anchor of quality or to drive educational processes within the organization). The scores are summed from responses of all 14 school leaders to determine the collective appraisal of each criterion's importance. The rank of each QC (indicating its importance to school leaders) is shown in brackets after its score.

The summed quality importance scores in columns B and C indicate the importance of each QC with transmissive weighting for each of the two groups of schools. Strongly transmissive-weighted QC are seen as anchors to secure long-lasting ESD implementation (see step 3 in the method section). Positive shifts in ranking of a QC from column A to column B or C indicate that it is relatively strongly favored as an anchor by the leaders of group 3 or group 1 schools, respectively.

\subsection{Schools Working from a Transformative Perspective-Group 3}

By investigating the QC that school leaders in group 3 (see Figure 1) regarded as most important from a transmissive perspective (according to rankings in Table 2), we can discern anchors of quality in school organizations with a predominantly transformative ESD orientation. These are the QC with rankings that rose with transmissive-weighting by leaders of these schools (see columns A and B in Table 2). These QC and their respective rank differences (in brackets) are listed below: 
- ESD as a point of departure for organizing the school

- School leader teamwork

- School leader inner conviction and philosophy

- International outlook

- Resistance of ESD implementation

- Scheduling-length

- Proactive leadership

- School climate

- School collaboration with society

- School identity in society

- Leadership focus

- Partial ESD implementation in school

- Trans-disciplinary scheduling

Passages in the transcripts associated with these transmissive-weighted QC were reanalyzed by emergent theme categorization to search for domains in which the school leaders pointed out important anchoring structures and routines for their respective schools' organization. This enabled analysis of how leaders of the most transformation-oriented schools regarded the importance of anchoring structures within their organizations.

\subsubsection{A Holistic Idea}

Anchoring a holistic idea that extends beyond the intermediate goals associated with school accountability was recognized as important by the leaders in group 3 schools in many ways. In the thematic analysis we found that they emphasized the need to anchor this holistic idea within the school organization in different ways, and even above and beyond the organization. Some claimed that political decisions or decisions taken at the administrative level above the local school organization are crucial to legitimize ESD as a driver of quality; as one school leader put it: "it was a conscious choice taken by the school board to work with ESD". Another school leader said that "the freedom given by school authorities in handling financial resources following each student on a school level is advantageous for the school (to maintain the holistic idea)", i.e., budgetary freedom enabled investment to support their holistic idea. "ESD-related investments can also be met by economic means" as another of these respondents said. Hence, political and economic tools are examples of routines and structures used to anchor ESD as a holistic vision in the organization of these schools.

These school leaders argued that within processes of change, such as ESD implementation, it is important to have the vision well anchored within the organization in all the local steering documents, otherwise the change will not have a specific direction. In describing a reorganization of the school, one school leader observed: "school managers were convinced and shared a common idea, which gave us uniform and consistent arguments that could be used for the rearrangements into new working teams in the school". Hence, by including the ESD perspective in the official documentation, the school leaders could legitimize and justify changes in a transformative direction.

The school leaders also addressed the importance of routines and anchors for focusing the teachers and organization as a whole on what is important, i.e., the common vision or holistic idea, as exemplified by the following quotation of a school leader: "I do not want all teachers to ask how they order a bus for a study trip or where to find paper for the copier, all such structures and routines have to be easy and transparent to all employers, so they can concentrate on our common idea in student engagement and classroom practice". Another school leader said:" It is important to remind teachers of the focus of our education, otherwise there is a risk that we'll do a lot of things without feeling satisfied in the long run .... To steer right (towards the overall objective) when there are a lot of educational milestones to meet is important". The school leaders all emphasized the need to not only have a holistic idea that unites students and teachers at the school, but also to instill routines and structures that make it possible to anchor the idea within the school's organization. 
One school leader even suggested that marketing was a way to anchor the holistic idea: "the international label makes us attractive in young people's choice of school to attend". Hence, through marketing this school created routines and structures for recruiting students each year, thereby facilitating (or even necessitating) deep and permanent instillation of ESD in the organization, and strong orientation towards ESD and serving societal needs in all the school's activities. Thus, instrumentalist transmissive goals were clearly used for transformative purposes.

\subsubsection{Collegial Approach}

The school leaders in the strongly transformation-oriented schools generally emphasized a collegial approach as a way of achieving quality in their organizations, and ESD provided a core vision for organizing and developing their teaching practices (unsurprisingly, as most of the participating schools had prior engagement with ESD). Accordingly, a school leader observed that "all teachers that originally applied for employment at this school shared the common idea (commitment to ESD) from the start". Similarly, leaders of one group 3 school claimed that their school differed from other schools in their structures and routines, in that all staff were committed, from recruitment, to a collegial approach to ESD implementation. This was manifested (in all group 3 schools) in the organization of teaching around students through teams of teachers of different disciplines. These teacher groups learned and taught ESD together through collegial discussions; as one school leader observed:" We have noticed that assessing student work is easier and the teachers' ability to assess knowledge has generally increased, comparisons between subjects indicate that and we think it is due to the arrangement of working teams".

The collegial approach was not only apparent in the structures of day-to-day management of teachers. It was also applied at school leader level to anchor ESD in collaboration within and between schools, to create a common professional understanding amongst school leaders as a collegial community, which required organized meetings. Such a community can provide a knowledge base and both practical and moral support for changes to routines and structures in school organization. A school leader expressed a strategy used in his/her school leader team as follows: "A school developer is employed and their role is to share the developer's ideas amongst the staff (in the sense of collegial sharing of an idea in the school leader team)". Further, school leaders noted the importance of sharing and involving others in their plans to involve and influence teachers in a collegial manner. On several occasions during the interviews, school leaders expressed interest in theories of collegial work that could be put into practice. One school changed the teachers' working conditions to oblige them to attend school during student holidays to "make space for collegial work together". According to that school leader, it would not be possible to accomplish real transformative changes without structural changes that anchored ESD through collegial communities, even if the new routines might be unpopular with staff.

A wider collegial approach was also seen as important by school leaders in terms of international collaborations, as they found that international contacts provided opportunities to learn and compare quality in education. As an anchor this was expressed as a means for comparing and ranking the school against others; as voiced by one school leader: "We went to the USA to compare how they work with computers in education". The trip was arranged to assess whether the system used at home was 'good enough', in comparison with American schools, or whether the school needed to improve. Trips such as these enable schools around the world to share experiences and establish common ground regarding the organization of high-quality education.

\subsubsection{ESD Protection by School Leadership}

A distinctive argument by school leaders for using anchors in transformation-oriented schools is that anchors are mainly needed to protect ESD implementation that has already been accomplished, rather than for furthering its implementation. The school leaders emphasized the importance of ESD and the political mandate to implement it. They also stressed the importance to schools of recognition 
for successful ESD implementation. One stated, "We have had support to deal with this specific issue (ESD) from the start". Another said, "We are part of an EU program and received an award for our contributions". The award was important to the school leader as proof that the school had anchored quality in its organization, thus the award justified and protected ESD, by legitimizing the school's work in international ranking systems.

The justification aspects also had claimed importance in relation to other schools and school leader colleagues: "We had collegial evaluations with other schools in nearby municipalities. We met by visiting each other's schools and considered strategies for conducting collegial evaluation". Hence, in the Swedish context, where schools need to prove their quality and compete for students and staff, ESD needs protection to remain embedded in schools' organization.

5.1.4. Summary of the Schools with a Transformation Orientation-Anchoring as a Way to Legitimize and Justify ESD

The school leaders in group 3 schools claimed that it is important to build anchoring structures and routines in schools' organizations around a vision or a holistic idea (specifically, ESD), i.e., to create documentation and routines that establish ESD as the school vision. They also recognized the importance of collegial work to organize ESD in teaching and learning in the organizations, and use of a proactive style of school leadership to protect and maintain ESD as a central idea within them. These seem to be the key domains to anchor ESD in a school's organization. Thus, school leaders anchor quality in their schools by ensuring that commitment to ESD permeates all the structures and routines of their respective organizations. Interestingly, we found that a major motive for using these anchors is the school leaders' perceived need to continuously legitimize and justify ESD within and outside the school organization. They felt a need to legitimize ESD in the eyes of external stakeholders, as well as teachers and students, through (inter alia) positioning it as core content of schooling in the guidance documents, awards and working processes.

\subsection{Schools without a Dominant Transformation Orientation-Group 1}

By identifying the QC that school leaders in group 1 weighted as most transmissive, we discerned anchors of quality in school organizations that lacked a dominant transformative ESD-orientation. These $\mathrm{QC}$ are those that showed a positive shift from their overall ranking in transmissive importance to their ranking by leaders of group 1 schools (columns A and C, respectively, in Table 2). The QC and their differences in rankings (in brackets) are listed below:

- Resistance of ESD implementation

- Partial ESD implementation

- School leader team work

- Role model leadership

- ESD quality measurement

- Long term plans

- Evaluation purpose

- Professional networks

- Proactive leadership

- External expectations

- School governance

- ESD purpose

- Team structure at school

- Implementation of holistic idea

Passages of the transcripts associated with identification of the transmissive-weighted QC were then reanalyzed by emergent theme categorization to search for themes in which the school leaders highlighted anchoring structures and routines as important for their schools' organization. This enabled us to analyze how leaders of schools with relatively weak transformation-oriented quality 
perspectives perceived the importance of anchoring structures within their respective organizations, and thus identification of potential obstacles to implementation of transformation-oriented education because they have not come so far in this process.

\subsubsection{Individual Responsibility}

Leaders of group 1 schools said that single individuals often drove and felt responsibility for ESD implementation in their respective organizations. No schools in this group took a 'whole school' approach for its implementation. In most cases, only a specific program or team of teachers was actively involved: "(Working with ESD) is unevenly distributed at the school, some parts of the organization work more frequently than others, we are an ordinary school where people are either interested or not". One school leader said: "a reorganization at the school caused a decline in ESD engagement by the staff ... (only) ... a few individuals in the same teacher team now legitimize the whole ESD work at our school". The rationale of the leaders in this group was to first anchor ESD in parts of the school organization, as benchmarks, before involving the whole organization. The leaders reported a struggle to interest staff in the ESD perspective in teaching: "this is an ordinary school with individuals that are positive and others that are negative (towards ESD)". Thus, they believed it is important to support certain groups and individuals within the school organization, in an attempt to secure quality and anchor ESD implementation in organizations where there is resistance to ESD. Since most interviewed school leaders described ESD as a collaborative engagement, they regarded resistant individuals and teacher teams as threats to ESD implementation: "Teachers are difficult to lead because they like to lead themselves, single individuals can therefore pose threats to common idea (such as ESD)". Another school leader claimed that, "the teachers prefer an autonomous work situation where leading them is problematic (in relation to new ideals that a school leader team wished to introduce in education)". Leaders of group 1 schools therefore claimed that it is important to show that ESD is "a way to organize the work efficiently to reduce the total collegial workload", i.e., to show the benefits of organizing the school around ESD from many perspectives. Several expressions by school leaders testify to the view that different functions within schools are associated with different responsibilities that should be assigned to different individuals, and that such an arrangement creates security in the workplace for all individuals. Anchoring quality by splitting responsibilities into manageable tasks for single individuals was claimed to be a way of organizing ESD: "I make sure time allowance for my staff is adjusted to their work performance (to make sure no-one is overloaded with work)" as one school leader put it. From passages related to this theme in the transcripts, we can conclude that linked features of the relatively weak transformation of group 1 schools include anchorage of ESD to individuals within the organization, partial ESD implementation and lack of consensus regarding ESD within the organization.

\subsubsection{Top-Down Management Style}

The leaders of group 1 schools tried to anchor ESD within the organization using a top-down leadership style, for example, using small sets of teachers in the schools to provide good examples for others to follow. One school leader said: "the education program involving ESD is only one of many programs, and this partial program is expected to validate the whole school's engagement in ESD". ESD validation was often conducted by the school leaders themselves, or by the active group of teachers, rather than by the organization as a whole, further indicating a top-down management anchoring process. As a result of reorganization, a teacher team working actively with ESD was split up; as the school leader noted, "it (the ESD perspective) is now latently present". Hence, a step-by-step implementation initiated from leadership level was expected to occur within these organizations that required anchoring support by a pronounced top-down management process. In another school that also had a reorganization, teachers that did not agree with the idea of ESD were "encouraged to find other teacher positions" by a school leader. 
The resistance to ESD implementation within the organizations at least partly explains the top-down approach to anchoring long-lasting ESD implementation in this group of schools. One of the leaders said, "clarity reduces disagreement, I refuse to listen to whining when decisions are preceded by opportunities (for teachers) to express themselves in open processes". The school leaders used various techniques to make sure their students and staff felt included, without involving them in the overall decision-making processes: "I spend time to get to know students' desires and demands to create an informed platform for my own decision-making". This leader apparently tried to understand the general view of the students so that she could consider it in her decision-making without directly involving the students. Thus the decision-making process included some possibility to consider students' needs and opinions, but it was anchored in a top-down leadership style.

\subsubsection{ESD Promotion by School Leadership}

Leaders of the less transformative (group 1) schools portrayed more rudimentary and partial ESD implementation in their organizations than the leaders of group 3 schools. Hence, in these schools anchoring structures were treated as ways to promote ESD, rather than protect it (as in group 3 schools). One of the school leaders compared the school with a business organization and says that "education is non-effective due to the unwillingness of staff to rearrange teaching effectively, interactions and traditions are hindering such rearrangements as ESD is an urgent issue". Another said that classroom visits were organized "to instill trust and encourage (teachers and students) to deal with complex ESD issues in the classroom". Thus, the school leaders often expressed a need to anchor ESD by promoting it within the school organization.

These school leaders also sought moral support to promote ESD, and reported that they often experienced pressure from colleagues, rather than support (as experienced by leaders of group 3 schools). One said, "I feel lonely in handling high pressure from my (educational) program to deliver in my role as school leader (i.e., meet demands and expectations of staff and students)". At the same time he claimed that he "wanted to unload teacher pressure (of ESD implementation) by placing the structural responsibility at the leadership level", i.e., by talking about ESD whenever he had a chance. In hiring new staff one school leader said, "only staff that accept the (ESD) project we are working with are welcome (at this school)", so promoting ESD in the recruitment process was an important way of anchoring ESD within the school organization.

\subsubsection{Anchoring ESD within the School Organization-Group 1}

The anchoring expressions identified by leaders of group 1 schools suggest they favored a 'minimalist approach' that seeks to secure the presence of ESD despite differences in perceptions of and resistance to ESD in the school organization. They anchored ESD around individuals or groups of individuals who were assigned responsibility for ESD. Further, ESD was anchored through top-down decision-making processes directed towards these individuals, not necessarily involving the whole organization. ESD was promoted by the school leaders in efforts to anchor ESD in other parts of the school organization. We can conclude that ESD in these schools was anchored by a leadership style that involved strong delegation of individual responsibility in the schools' organization. These features could be interpreted as signs of an early stage of ESD implementation, as school leaders expressed difficulties in scaling up ESD in these schools.

\section{Discussion}

Our results show that factors often criticized in research as negative and counterproductive regarding a transformative perspective on ESD-i.e., a high emphasis on structures and routines in school organizational settings $[7,22,43]$-may also function as fundamental anchors for successful ESD implementation. The transformative oriented schools in this study emphasize that anchoring structures and routines are important in order to build a vision or a holistic idea around ESD. Moreover, collegial work methods and groups need to be constituted within the organization as a way of organizing ESD in 
teaching and learning. Last, but not least, the school leader needs to adopt a proactive leadership style to protect and create support structures that maintain ESD as a central idea within the organization. These domains we would claim, based on our study, are important for other schools that aspire to implement ESD from a transformative perspective, to work strategically and build organizational routines and structures in order to anchor ESD within the organization. These anchors are crucial in creating a resilient organization that is not reliant on particular members of staff that act as 'driving souls' for ESD, a common problem recognized within ESD implementation efforts [46,47]. Hence, in order to make ESD permanent within the whole school organization, ESD needs to be firmly anchored within the organization around these domains. The interplay between strong transformative structures and routines at the organizational level has been discussed by Nikel and Lowe [12]. In this this study we have shown empirically how these anchors are used, and can be used as benchmarks for other schools aiming to implement ESD from a transformative perspective with the aim of establishing a true whole school approach towards ESD, which is recognized to be important in the literature for true ESD implementation $[5,40]$.

We now turn to the other group of schools, the ones selected on the basis of not emphasizing transformative aspects of education, showing less openness to changes in society and less focus on student learning processes. However, it is important to remember that these schools have also embraced ESD and are actively trying to implement ESD. As we know, ESD as a framework is highly influenced by transformative perspectives on education [10] and, as could be expected, these schools have problems anchoring ESD within their school organizations. Although, there is willingness and intent, there exists resistance within the school organization. Hence, the domains where these schools try to anchor ESD reflects this context of resistance. For these schools, the aim for the school leadership is to promote rather than to protect ESD within the school organization. This is accomplished mainly by anchoring through top-down direction, not through collegial processes found in the more transformative schools. School leaders expect specific teachers or groups of teachers to take responsibility for ESD implementation, with the remaining staff having little or no engagement with ESD activities. These structures and routines of individualization used to secure ESD are at the same time making the perspective separate from the whole organization. In that way, there are less visible signs of any routines and structures anchoring ESD within the whole organization in less transformative schools compared to the more transformative schools.

The questions to answer are (i) whether these schools are at the beginning of a path to implement ESD; and (ii) if this strategy of using individual responsibility and top-down management style can be seen as a first step, before developing routines and structures anchoring ESD through collegial processes. We do not have data to fully answer these important questions. However, based on our selection of schools we know that the less transformative schools have been actively trying to implement ESD for many years and approximately the same length of time as the transformative schools. Hence, a cautious conclusion is that it is more likely that these schools are unlikely to be able to develop a mature ESD implementation. Our recommendation, therefore, is that other schools avoid this path, and instead, try to establish from the outset the same anchors adopted by more transformative schools. A limitation of the study is that domains in the school organization that are identified as important anchors for ESD implementation (holistic ideas, visions and collegial work) do not always exist in less transformative schools. It is thus hard to generalize the findings in the study to all schools. However, more research is needed to fully confirm the robustness of this conclusion and if identified anchors could also become applicable to less transformative school organizations.

\subsection{Legitimization and Justification of the School Organization}

One important finding of this study is that the school leaders of the transformative oriented schools expressed a need to legitimize and justify ESD within the school organization as well as in relation to stakeholders outside the school. It was important to build structures and routines as a way to anchor ESD. One example of a legitimizing activity is the support and decisions made at 
the political level in favor of ESD. School leaders express such external pressure as positive and a justification for ESD implementation within the whole school organization. In line with this finding, Giles and Hargreaves [50] noted the importance of political support, collaboration with other schools and guidance based on a holistic and shared idea as being crucial for the long-lasting implementation of the ESD perspective. Our results point in the same direction, based on the ways in which school leaders in the transformative schools address these issues. However, the novel contribution of this study is that the school leaders point out the need to use routines and structures to legitimize and justify these transformative perspectives in a transmissive way, within and outside the school organization. Hence, building transformative schools is not just about breaking down boundaries between the school and the surrounding society, but also about building boundaries within the schools to legitimize and justify ESD.

Holmberg, Svanström, Peet et al. [56] observed that securing legitimacy in the organization to work with sustainable issues is also essential for successful ESD implementation. Interestingly, Kaser and Halbert [47] found in a literature review on transformative leadership that the leadership strategy "evidence seeking in action", describes a way of accomplishing long-term and lasting changes (anchoring) in school organizations. When new perspectives such as ESD are introduced into the school organization, knowledge of how one expects the quality of student outcomes to improve and the role of leadership are studied through a known pattern of structures and routines [57]. A framework systematically embedding the new perspective into the structures and routines of school organization can make the relevance of the perspective explicit and ensure adherence to it by the staff in the organization [45]. Our study shows that this strategy is really implemented by transformative ESD schools in Sweden, indicating that these schools have built resilient school organizations that are not dependent on individual "driving souls" for the implementation of ESD.

\subsection{A Search of Stakeholders for Legitimizing ESD}

Role model schools are often used as cases to study and develop ways of implementing ESD [10,26]. This study uses a similar approach, and its main contribution is a better understanding of where in the school organization that structures and routines are needed to accomplish transformative ESD implementation. Thus the results of this study could provide the basis for recommendations in ESD implementation programs as a way to scale up ESD in whole school approaches [40].

In conducting this study, it was surprising that the participating schools did not emphasize the importance of linking their school organizations to the local society in anchoring ESD for a far-reaching cooperation. The overall aim with ESD is to have an impact on sustainable development locally, according to research [1] and policy [8], an issue that is also central in most ESD implementation programs [15-19]. The important anchors, from the perspective of the participating schools, however, were internal aspects of the school organization (e.g., holistic ideologies, collegial collaboration) or remote stakeholders such as international schools. Local stakeholders are mentioned, but are used as anchors to a lesser degree. According to Earl [58], it is those things closely associated with learners and teachers that ultimately lead to a long-lasting anchored transformation of education, although this is not a prominent feature in our results. Thus, the following question should be targeted as a very important issue for future studies to pursue and investigate further: To what degree are local stakeholders necessary for making ESD a permanent and long lasting endeavor?

\section{Conclusions}

Our study contributes insights into domains of the school organization where school leaders believe structures and routines are required to anchor ESD. Recommended practices to broaden successful ESD implementation in schools and Sustainability School Programs could potentially include:

- Manifestation of ESD in each school's vision and holistic idea to prevent its neglect. School leaders find a documented vision helpful for legitimizing and justifying transformative educational changes. The routines associated with a vision and central idea also lead the teachers and 
organization as a whole to focus on important elements for continuously evaluating changes in practical education in relation to the idea of ESD laid out in the school's holistic vision.

- Planning for collegial work to organize ESD. Interdisciplinary work that involves teams of teachers is recommended, thus there are needs to coordinate teachers' schedules and establish a culture that encourages trials of new ways of teaching. Collegial organization of principals is also valuable to allow them to support each other in trials of new paths to enhance transformative education.

- Nurturing a proactive school leadership style that protects and maintains ESD as the central idea within the organization when it is questioned and criticized by others. Legitimization by the leadership, preferably with support from the political school board level and municipal stakeholders. School leaders should also robustly defend the embrace of transformative education in their organization, and clearly explain its positive effects on ESD implementation and more general education.

Leaders of schools less focused on transformative perspectives anchor ESD around individuals or a group of individuals that are given responsibility for its implementation. In these cases, ESD is anchored through top-down decision-making processes directed towards these individuals, which do not usually involve the whole organization. The main reason for anchoring ESD in this way is to circumvent resistance to ESD within the school organization. This mode of anchoring ESD could be an initial step in implementing ESD, but is more likely to lead to incomplete or unsuccessful implementation (as some schools had been actively implementing ESD for many years, with limited success).

In summary, the fundamental finding is that it is important to build transmissive routines and structures in some domains for successful, permanent, transformation-oriented ESD implementation within a school's organization. However, more research is needed to obtain clear indications of optimal strategies for schools with low levels of transformative activities. For example, there may be intermediate stages for school organizations to support transformative ESD implementation that we have not detected, but could assist schools in progressing from partial implementation of ESD through delegation of responsibilities to individuals towards more collegial and holistic efforts. More research is needed to evaluate these hypotheses.

Author Contributions: N.G. and A.M. designed the study. A.M. collected and analyzed the data. N.G. and A.M. interpreted the outcomes of the statistical analysis and wrote the paper with A.M. as main author.

Funding: The authors gratefully acknowledge The Swedish Institute for Educational Research (project 2017-00065) for funding this study.

Acknowledgments: The authors would like to thank all the participating school leaders and teachers who took part in the study.

Conflicts of Interest: The authors declare no conflict of interest.

\section{References}

1. Gross, D.; Nakayama, S. Drivers and barriers to implementing ESD with focus on UNESCO's action and strategy goals for the second half of the decade. Glob. Environ. Res. 2010, 15, 125-136.

2. Breiting, S.; Wickenberg, P. The progressive development of environmental education in Sweden and Denmark. Environ. Educ. Res. 2010, 16, 9-37. [CrossRef]

3. Olsson, D.; Gericke, N.; Chang Rundgren, S. The effect of implementation of education for sustainable development in Swedish compulsory schools-Assessing pupils' sustainability consciousness. J. Environ. Educ. 2016, 22, 176-202. [CrossRef]

4. Berglund, T.; Gericke, N.; Chang Rundgren, S. The implementation of education for sustainable development in Sweden: Investigating the sustainability consciousness among upper secondary students. Res. Sci. Technol. Educ. 2014, 32, 318-339. [CrossRef]

5. Hargreaves, L. The whole-school approach to education for sustainable development: From pilot projects to systemic change. Policy Pract. Dev. Educ. Rev. 2008, 6, 69-74. 
6. Lotz-Sisitka, H.; Wals, A.; Kronlid, D.; McGarry, D. Transformative, transgressive social learning: Rethinking higher education pedagogy in times of systemic global dysfunction. Curr. Opin. Environ. Sustain. 2015, 16, 73-80. [CrossRef]

7. Mogensen, F.; Schnack, K. The action competence approach and the 'new' discourses of education for sustainable development, competence and quality criteria. Environ. Educ. Res. 2010, 16, 59-74. [CrossRef]

8. United Nations. Sustainable Development Goals. 17 Goals to Transform Our World. Available online: http://www.un.org/sustainabledevelopment/education/ (accessed on 23 October 2018).

9. Mogren, A.; Gericke, N. ESD implementation at the school organization level, part 1-Investigating the quality criteria guiding school leaders' work at recognized ESD schools. Environ. Educ. Res. 2017, 23, 972-992. [CrossRef]

10. Mogren, A.; Gericke, N. ESD implementation at the school organization level, part 2-Investigating the transformative perspective in school leaders' quality strategies at ESD schools. Environ. Educ. Res. 2017, 23, 993-1014. [CrossRef]

11. Mogren, A; Gericke, N.; Scherp, H.-Å. Whole school approaches to education for sustainable development: A model that links to school improvement. Environ. Educ. Res. 2018, 1-24. [CrossRef]

12. Nikel, J.; Lowe, J. Talking of fabric: A multi-dimensional model of quality in education. Compare 2010, 40, 589-605. [CrossRef]

13. Holmberg, J.; Lundqvist, U.; Svanström, M.; Gröndahl, F.; Arehag, M. The university and transformation towards sustainability: The strategy used at Chalmers university of technology. Int. J. Sustain. High. Educ. 2012, 13, 219-231. [CrossRef]

14. Scott, W. Education for Sustainable Development (ESD): A critical review of concept, potential and risk. In Schooling for Sustainable Development in Europe; Jucker, R., Reiner, M., Eds.; Springer International Publishing: Cham, Switzerland; Heidelberg, Germany; New York, NY, USA, 2016; pp. 47-69, ISBN 978-3-319-09548-6.

15. Eco Schools. Available online: http://www.ecoschools.global (accessed on 5 June 2018).

16. Green School Alliance. Available online: http://www.greenschoolsalliance.org/home (accessed on 22 October 2018).

17. The Australian Sustainable School Initiative. AuSSI. Available online: http://www.education4sustainability. org/2012/08/21/the-australian-sustainable-schools-initiative-aussi/ (accessed on 16 November 2016).

18. Sustainable Schools in the UK (SEED). Available online: http://se-ed.co.uk/edu/sustainable-schools/ (accessed on 16 November 2016).

19. The Swedish National Agency for Education. Award for Sustainable Schools. Available online: http: //www.skolverket.se/skolutveckling/miljo-och-halsa/hallbar-utveckling/ (accessed on 27 April 2016).

20. UNESCO. United Nations Decade of Education for Sustainable Development 2005-2014, Draft International Implementation Scheme. United Nations Educational, Scientific and Cultural Organization. Available online: http://unesdoc.unesco.org/images/0013/001399/139937e.pdf (accessed on 23 October 2018).

21. Sterling, S. Separate tracks or real synergy? Achieving a closer relationship between education and SD, Post-2015. J. Educ. Sustain. Dev. 2014, 8, 89-112. [CrossRef]

22. Jickling, B.; Wals, A. Debating education for sustainable development 20 years after Rio: A conversation between Bob Jickling and Arjen Wals. J. Educ. Sustain. Dev. 2012, 6, 49-57. [CrossRef]

23. Rickinson, M.; Hall, M.; Reid, A. Sustainable schools programmes: What influence on schools and how do we know? Environ. Educ. Res. 2016, 22, 360-389. [CrossRef]

24. United Nations Educational, Scientific and Cultural Organization. Roadmap for Implementing the Global Action Programme on Education for Sustainable Development; United Nations Educational, Scientific and Cultural Organization: Paris, France, 2014.

25. Sund, P. Experienced ESD-Schoolteachers' teaching-An issue of complexity. Environ. Educ. Res. 2015, 21, 24-44. [CrossRef]

26. Laurie, R.; Nonoyama-Tarumi, Y.; McKeown, R.; Hopkins, C. Contributions of education for sustainable development (ESD) to quality education: A synthesis of research. J. Educ. Sustain. Dev. 2016, 10, $226-242$. [CrossRef]

27. Martin, S.; Dillon, J.; Higgins, P.; Peters, C.; Scott, W. Divergent evolution in education for sustainable development policy in the United Kingdom: Current status, best practice, and opportunities for the future. Sustainability 2013, 5, 1522-1544. [CrossRef] 
28. Scott, W. Exploring a transformative orientation to sustainability in universities: A question of loose and tight Framings. Environ. Educ. Res. 2015, 21, 943-953. [CrossRef]

29. Boeve-de Pauw, J.; Van Petegem, P. The effect of Flemish eco-schools on student environmental knowledge, attitudes, and affect. Int. J. Sci. Educ. 2011, 11, 1513-1538. [CrossRef]

30. Boeve-de Pauw, J.; Gericke, N.; Olsson, D.; Berglund, T. The effectiveness of education for sustainable development. Sustainability 2015, 7, 15693-15717. [CrossRef]

31. Warner, B.; Elser, M. How do sustainable schools integrate sustainability education? An assessment of certified sustainable K-12 schools in the United States. J. Environ. Educ. 2015, 46, 1-22. [CrossRef]

32. Hargreaves, A.; Fink, D. The seven principles of sustainable leadership. Educ. Leadersh. 2004, 61, 8-13.

33. Scott, W. Developing the sustainable school: Thinking the issues through. Curric. J. 2013, 24, 181-205. [CrossRef]

34. Scott, W.; Gough, S. Sustainable Development and Learning; Routledge: London, UK, 2003; ISBN 9780415276474.

35. Hargreaves, A.; Shirley, D. The Fourth Way: The Inspiring Future for Educational Change; Corwin Press: Thousand Oaks, CA, USA, 2009; ISBN 978-1-4129-7637-4.

36. Bottery, M.; Wright, N.; James, S. Personality, moral purpose and the leadership of an education for sustainable development. Education 3-13 2012, 40, 227-241. [CrossRef]

37. Breiting, S.; Mayer, M.; Mogensen, F. Quality Criteria for ESD-Schools: Guidelines to Enhance the Quality of Education for Sustainable Development; Stollfu.Verlag Bonn GmbH \& KG: Vienna, Austria, 2005. Available online: https://www.ensi.org/global/downloads/Publications/208/QC-GB.pdf (accessed on 5 June 2018).

38. Vare, P.; Scott, W. Learning for a change: Exploring the relationship between education and sustainable development. J. Educ. Sustain. Dev. 2007, 1, 191-198. [CrossRef]

39. Reid, A.; Nikel, J.; Scott, W. Indicators for Education for Sustainable Development: A Report on Perspectives, Challenges and Progress; Centre for Research in Education and the Environment: Bath, UK, 2006. Available online: https://pdfs.semanticscholar.org/0ef8/0d0e25dcb3a7c04d9d5c473be1a564ad2af6.pdf (accessed on 23 October 2018).

40. Reiner, M. A whole school approach to sustainable development: Elements of education for sustainable development and students' competencies for sustainable development. In Schooling for Sustainable Development in Europe; Jucker, R., Reiner, M., Eds.; Springer International Publishing: Cham, Switzerland; Heidelberg, Germany; New York, NY, USA; Dordrecht, The Netherlands; London, UK, 2016; pp. 15-30, ISBN 978-3-319-09548-6.

41. Madsen, K. Unfolding education for sustainable development as didactic thinking and practice. Sustainability 2013, 5, 3771-3782. [CrossRef]

42. Öhman, J. Values and Democracy in Education for Sustainable Development: Contributions from Swedish Research; Liber: Malmö, Sweden, 2008; ISBN 978-91-47-088515.

43. Peters, M.; Wals, A. Transgressive learning in times of global systemic dysfunction: Interview with Arjen Wals. Open Rev. Educ. Res. 2016, 3, 179-189. [CrossRef]

44. Mezirow, J. An overview on transformative learning. In Contemporary Theories of Learning: Learning Theorists in Their Own Words; Illeris, K., Ed.; Routledge: London, UK, 2009; pp. 90-105, ISBN 9781135226336.

45. Kaser, L.; Halbert, J. Leadership Mindsets: Innovation and Learning in the Transformation of Schools; Routledge: London, UK, 2009; ISBN 9781134022588.

46. Wickenberg, P. 'Souls of fire', change agents and social norms. In Social and Legal Norms. Towards a Socio-legal Understanding of Normativity; Baier, M., Ed.; Routledge: London, UK; New York, NY, USA, 2013; pp. 209-230, ISBN 978-1409453437.

47. Varga, M.; Kuehr, R. Integrative approaches towards zero emissions regional planning: Synergies of concepts. J. Clean. Prod. 2007, 15, 1373-1381. [CrossRef]

48. Giles, C.; Hargreaves, A. The sustainability of innovative schools as learning organizations and professional learning communities during standardized reform. Educ. Adm. Q. 2006, 42, 124-156. [CrossRef]

49. Sundberg, D. Skolreformernas Dilemman: En Läroplansteoretisk Studie av Kampen om tid i den Svenska Obligatoriska Skolan. [School Reforms Dilemmas: A Curriculum Theoretical Study of the Battle for Time in the Swedish Compulsory School]. Ph.D. Thesis, Växjö University, Växjö, Sweden, 2005.

50. Scherp, H.-Å.; Scherp, G. Lärande och Skolutveckling, Ledarskap för Demokrati och Meningsskapande [Learning and School Improvement, Leadership for Democracy and Meaning Making]; Estetisk-filosofiska fakulteten; Karlstad Universitet: Karlstad, Sweden, 2007; ISBN 91-7063-105-0. 
51. Foundation for Environmental Education, Håll Sverige Rent, Grön Flagg. Available online: http://www.hsr.se (accessed on 23 March 2015).

52. Swedish Council for Higher Education, The Global School Program. Available online: https://www.utbyten. se/mojligheter/mojligheter-inom-forskola-och-skola/den-globala-skolan/ (accessed on 23 October 2018).

53. Scherp, H.-Å. Quantifying qualitative data using cognitive Maps. Int. J. Res. Method Educ. 2013, 36, 67-81. [CrossRef]

54. Fraenkel, J.; Wallen, N.; Hyun, H. How to Design and Evaluate Research in Education; McGraw-Hill Humanities/Social Sciences/Languages: New York, NY, USA, 2014; Volume 7, ISBN 9781259253928.

55. Weber, L.M. Basic Content Analysis, 2nd ed.; Sage Publications: Newbury Park, London, UK; New Deli, India, 1990; ISBN 9780803938632.

56. Holmberg, J.; Svanström, M.; Peet, D.J.; Mulder, K.; Ferrer-Balas, D.; Segalàs, J. Embedding sustainability in higher education through interaction with lecturers: Case studies from three european technical universities. Eur. J. Eng. Educ. 2008, 33, 271-282. [CrossRef]

57. Creemers, B.P.; Reezigt, G.J. School effectiveness and school improvement: Sustaining links. Sch. Eff. Sch. Improv. 1997, 8, 396-429. [CrossRef]

58. Earl, L. Understanding How evidence and learning conversations work. In Professional Learning Conversations: Challenges in Using Evidence for Improvement; Earl, L., Timperley, H., Eds.; Springer Science \& Business Media, Aporia Consulting Ltd.: Toronto, ON, Canada, 2008; Volume 1, pp. 1-12, ISBN 978-1-4020-6917-8.

(C) 2019 by the authors. Licensee MDPI, Basel, Switzerland. This article is an open access article distributed under the terms and conditions of the Creative Commons Attribution (CC BY) license (http://creativecommons.org/licenses/by/4.0/). 